Send your letters to the Editor, British

Dental Journal, 64 Wimpole Street, London W1G8YS E-mail bdj@bda.org

Priority will be given to letters less than 500 words long. Authors must sign the letter, which may be edited for reasons of space.

\section{Public identities}

Sir, I read with unease the news item Dentists' addresses to go online (BDJ 2006; 201: 495). The decision to publish the full addresses of GDC registered dental professionals online is, I feel, entirely unnecessary, and does not take account of the difficulties this may be causing to a not insignificant proportion of dental professionals and DCPs.

The alternative options given to having my home address published online include using my work address, or setting up a P. O. Box address. While I have no objection to my work address being shown online, I have been advised by the GDC that all correspondence will also be sent to this address. While this option may be suitable for most registered professionals, I would like to highlight that it is by no means universally acceptable.

My personal situation is that I am currently working as a Senior House Officer, and due to the rotational nature of these positions, my work address is likely to change a number of times in the next 12 months. I therefore feel that it would not be appropriate for me to select this as a mailing address, due to the possibility of important post going astray.

The remaining solution is to set up a P. O. Box address. It is a rather bitter pill to swallow that after having already paid my ARF of $£ 420$, I will need to pay a further $£ 60$ annually to set this up, with the added inconvenience of having to regularly travel to check for any correspondence from the GDC.

The news that my full home address may already have been divulged by the GDC, on application, is also a rather unsettling thought. I cannot see any benefit to patients or the general public of having access to this information.

Perhaps a better option would be to publish a dental professional's work address, and have a separate, computerbased mailing list, which should be as easy to amend as information entered onto the website. Or maybe to follow the example of the GMC website, which reveals only the year and place of each professional's primary medical degree?

With identity theft emerging as one of Britain's fastest growing crimes, and reports of patients stalking healthcare workers by no means unreported, ${ }^{1}$ I feel that divulging personal information in such an easily-accessible public domain as the internet may not be entirely appropriate. With data protection laws for our patients becoming increasingly more stringent, are we not also entitled to some degree of protection?

\section{E. Molyneux}

Liverpool

1. Pathé M T, Mullen P E, Purcell R. Patients who stalk their doctors: their motives and management. Med J Australia 2002; 176: 335-338.

Duncan Rudkin, GDC Chief Executive and Registrar responds: Thank you for giving me the opportunity to respond to this letter. We do understand the concerns that L. Molyneux and other registrants may have about their full registered address being published on our online registers, and would like to take this opportunity to explain the reasons behind the Council's decision.

The GDC's registers are at the very heart of our work to protect patients. They are the means by which patients and professionals can check somebody is licensed to work as a dental professional in the UK. As such, a dental professional's registered address has always been public information.

With a much more mobile profession, the printed copies had increasingly become an anachronism, containing information that was out of date before it even reached the libraries. As it is our duty to make available accurate versions of our registers, the Council agreed the registers should no longer be available in printed format and we added full registered addresses to our website earlier this year. Before we took this decision, we contacted the Information Commissioner to ensure we would not be in breach of the Data Protection Act. We also took care to let professionals know well in advance that we would be doing so, enabling them to amend their details if they wished.

Introducing a second correspondence address (in addition to the registered

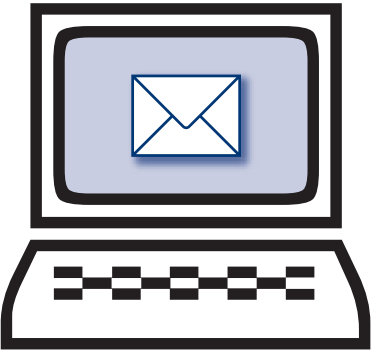

address) has the potential to damage the integrity of our registers. By definition we need to hold one registered address for registrants and, by law, we are required to use a registered address when we send certain documents; patients are also entitled to this same public information should they wish to contact a dental professional. The introduction of a correspondence address would also place a burden on registrants to keep two addresses up to date. The registered addresses we are required to publish by law could quickly become out of date.

I understand L. Molyneux's concerns with choosing a work address as a registered address when this is likely to change a number of times over a year. However, I would stress that registrants can change their address very quickly and simply by contacting us on 020 78873800 or by email: GDCregistration@gdc-uk.org. doi: 10.1038/bdj.2007.275

\section{Conflict resolution}

Sir, I was saddened to read of the problems relating to abuse that some dental surgeries face including that in which your correspondent $S$. Abassalty is practice manager (BDJ 2007; 202: 56). I would therefore like to bring to readers' attention the great deal of work now being done to prevent such incidents occurring, and to support staff members if they are unfortunate enough to be subjected to violence or abuse.

The NHS Security Management Service is currently working with the police to ensure that all incidents of violence and abuse against staff providing NHS services are investigated. There is also guidance available from the NHS SMS for NHS staff dealing with abusive patients (see http://www.cfsms.nhs.uk/ pubs/sms.gen.pubs.html). Training in conflict resolution should in addition be provided for all frontline staff providing NHS services through the commissioning PCT. This includes administrative and reception staff where they come into contact with members of the public in the course of their work.

It is, however, vital that all incidents 
of violence or abuse are reported to the Local Security Management Specialist within the local PCT promptly. This ensures that action can be taken and lessons learned to inform future measures taken on a national basis.

Abuse is a problem which can have very serious effects on those who experience it, but the NHS SMS is committed to helping those on the NHS frontline. With accurate and timely reporting from primary care staff, the NHS SMS and locally based NHS security management specialists can do a great deal to support staff members who are the victims of abuse or violence.

C. Ludford

NHS Security Management Service doi: 10.1038/bdj.2007.276

\section{Compromised insertion}

Sir, surgical procedures for clinical crown augmentation are frequently performed in the dental clinic. However, there are some clinical presentations, like the absence of space between tooth crowns and roots, where the insertion of periodontal files (Schluger and Sugarman's type) and surgical burs to remove bone tissue are compromised. We suggest the use of endodontical $\mathrm{K}$ files to perform interdental ostectomy in areas that are difficult to access. We recommend holding the instrument with a needle holder or haemostatic forceps to facilitate access to these areas. We should always keep in mind the possibility of fracture of the endodontic file. We have been using this technique with success for two years without complications.

I. G. Pedron, S. C. P. Kaba, É. H. Shinohara Brazil

doi: 10.1038/bdj.2007.277

\section{No passage to Indians}

Sir, we recently noticed that the UK Government adopted a policy to recruit medical doctors of European origin only. This was condemned by the British Association of Physicians of Indian Origin (BAPIO). It is a notable fact that there are thousands of dentists from developing countries, including India, who aspire to obtaining a practising licence in the UK so as to have a better quality of life, many of them taking out huge loans to pay for the International Qualifying Examination (IQE) and also paying travel expenses to the UK hoping to pass the exams and obtain employment. Just over a year ago there was a shortage of dentists in the UK and foreign trained dentists were needed to fill the vacancies in the UK. Many distinguished staff from the UK trained Indian dentists to take the IQE. It is a sad fact that these dentists, after investing huge sums of money, do not know what the future holds for them in the UK as there is no place for them in the NHS. Opportunities in private practice are also very bleak as dentists need to undergo vocational training prior to seeking employment. The few vacancies that are available for vocational training are filled by dental graduates from the UK or the EU.

There are approximately 2,500 dentists in India who have registered or are preparing to take various parts of the IQE. These dentists are now totally disillusioned and do not know what to do or where they stand! It would be very kind if the UK Government were to reconsider its stringent policy as it could be a life saver for dentists who have already taken or who are in the process of taking the IQE. Indian doctors and dentists have been serving in the UK for a long time and have made great contributions to the industry; they would continue to do so if the doors to the UK are kept open and they are not asked to return to India. Meghashyam Bhat

(This author wishes to point out that he was also the author of Preventing a dropout [BD] 2007; 202: 176-177] in which his name was given as just 'M. Bhat'.)

Manipal

doi: 10.1038/bdj.2007.278

\section{Close partnerships}

Sir, we were very interested to read the recent letter from S. Ifeacho regarding dental patients in A\&tE (BDJ 2007; 202: 2).

We are currently monitoring the number of dental patients and their treatment at the Emergency Department (ED) at Salisbury District Hospital.

An average of 26 dental patients are seen every month in the ED. Using data available we predict that there will be a $23 \%$ increase in dental attendances in the year following the introduction of the new dental contracts.

The Oral and Maxillofacial team have worked closely with the ED to develop algorithms for the assessment and treatment of dental patients in the ED. These have been welcomed by staff in the ED and result in $68 \%$ of patients being appropriately dealt with in the department without the need for further referral.

We highly commend and support the idea of establishing close working partnerships between EDs and local GDPs. We believe that this will benefit all those involved, especially the patients. J. K. Scott, I. P. Downie, N. Robinson Salisbury District Hospital doi: 10.1038/bdj.2007.279

\section{Unacknowledged}

Sir, we were extremely pleased to see the inclusion of the paper by Heidari et al. that highlights the compromised general and oral health of remand prisoners (BDJ 2007; 202: E5).

The Department of Community Special Care Dentistry within King's College London Dental Institute has been involved in the provision of dental services within prisons for almost 10 years including within HMP Brixton, Feltham Young Offenders Institute and HMP Belmarsh.

It was, in fact, while a member of this department that the primary author was given the opportunity to work within the prison dental services and was later funded by the department to undertake this research as part of her MSc in Sedation and Special Care Dentistry.

We were therefore extremely disappointed that, given the department's involvement in the provision of dental services within HMP Brixton, together with the department's support to the primary author while undertaking this research, there was no acknowledgement of this within the summary that appeared in the BDJ. This disappointment was greatly shared by all senior dental officer colleagues within our department, some of whom have themselves over the years provided dental care within the prison service.

We are very pleased to note in the full text of the paper available on the $B D J$ website that the primary author expressed her appreciation to the Consultant/Head of Department, Dr Liana Zoitopoulos, for the support that allowed this study to be undertaken. However, in our opinion both the summary published in the $B D J$ and the full text do not properly portray the role of the Department of Community Special Care Dentistry within this research or in the provision of dental care to prisoners within HMP Brixton.

Readers of the $B D J$ who only read the summary of this article and do not avail themselves of the full text would, we believe, incorrectly assume that this research was undertaken by another department where the primary author now works as there is no acknowledgement of ours.

We felt very strongly that we should write to bring our concerns to your attention as this research would not have been possible without the clinical, administrative and operational management support provided by the Department of Community Special Care Dentistry. Without this departmental infrastructure we would have been 
unable to tender for the contract and ultimately provide oral health dental care for prisoners within HMP Brixton.

R. Hale, P. Lisowska, T. Papadakis,

S. Mugwanya, A. Qureshi, Y. Tanna,

H. Bembridge, G. Palmer

London

doi: $10.1038 /$ bdj.2007.280

\section{Mealy-mouthed rhetoric}

Sir, could we congratulate you on the excellent editorial Someone needs to get a grip (BDJ 2007; 202: 111). However, irrespective as to whether or not a single body is required to deal with personnel requirements, the methodology used is of far greater importance.

The Department of Health has continued to rely upon a supply and demand model to estimate personnel requirements with its emphasis on bean counting. The shortcomings of such an approach have been highlighted elsewhere; simulation models are at best ineffective and at worst, provide misleading solutions with expensive financial and political consequences. ${ }^{1}$ These are exactly the issues highlighted in the editorial. Until the Department of Health accept that such an approach is outmoded, indeed worse than useless, the mistakes made will continue.

The purpose of modelling is not for predictive purposes; it is to examine the acceptability of policy options. Modelling should explore the viability of alternative future systems, discover unexpected problems from resource stress and produce a management tool to aid selection of best policy. ${ }^{2}$

A start would be for the Department to specify exactly what is meant by 'NHS dentistry' and stop hiding behind mealy-mouthed rhetoric if we are to prevent the creation of a generation of unemployed, disillusioned but talented and costly trained individuals. Given the present Government's performance in other areas of policy we hold out little hope.

P. Batchelor, R. Ladwa

By email

1. Batchelor PA. Can we plan workforce requirements? Comm Dent Health 2002; 19: 129-130.

2. Bronkhurst E M, Truin G-J, Batchelor P A et al. Health through oral health; guidelines for planning and monitoring for oral health care: a critical comment on the WHO model. J Public Health Dent 1991; 51: 223-227.

doi: 10.1038/bdj.2007.281

\section{Eyeball teeth}

Sir, I read with interest the article in The Times (Friday 2 March) stating that dental X-rays were to be used to help determine the age of asylum seekers to prevent abuse of the system. Presumably, these X-rays will be administered by suitably qualified staff. I don't remember being taught this reason for justification during my studies. Would it not be easier for these same staff to merely 'eyeball' the individual's dentition to glean this information, thereby minimising the radiation dose to the subject? Cheaper also.

\section{J. P. Beaumont}

Manchester

Editor-in-Chief's note: The BDA issued the following statement at the time of the proposal indicating its opposition to the use of radiation in this way:

'The BDA is vigorously opposed to the use of dental $X$-rays to determine whether asylum seekers have reached 18. This is an inaccurate method for assessing this age. We also believe that it is inappropriate and unethical to take radiographs of people when there is no health benefit for them.'

doi: 10.1038/bdj.2007.282

\section{UDA calculations}

Sir, I am writing to you after considerable correspondence with:

1. Rosie Winterton (useless)

2. Business Services Department (helpful);

3. Chief Dental Officer (evasive in this matter).

During the 'trial year' any claim including an extraction or a filling was counted as 3 UDAs. Now we are asked to only claim 1.2 for urgent cases of filling or extraction.

In a practice like mine with long established patients, often treatment due to a chipped tooth or a broken filling is needed on an occasional basis ie between examination visits.

Statistically each time I charge band 1.2 for a filling or extraction, I am losing 1.8 UDAs according to the trial year calculations.

I have asked for this matter to be put before the Implementation Group; I am told it has been. If no action is taken this means the fraudulent calculations are being left uncorrected.

This matter would go some way to explaining why some practitioners are having difficulty attaining their set UDAs.

I have very considerable correspondence to back up this letter. I am thoroughly fed up with a number of aspects of GDS but this is fraud.

\section{J. F. Sharp}

Ipswich

doi: 10.1038/bdj.2007.283 